\title{
A VIDA RURAL NA INGLATERRA
}

\section{(Washington Irving)}

O estrangeiro que quizer formar uma opinião exacta do caracter inglez, não deve limitar suas observações á metropole. Deve ir além, ao campo; deve permanecer algum tempo nas aldeias e logarejos; deve visitar castellos, villas, herdades e casas de campo; deve vaguear pelos parques e jardins; costeando as sebes e os verdes renques de arvores; deve demorar-se nas egrejas campezinas; assistir ás noites veladas e a outras festividades ruraes; e entreter-se com o povo, apreciando-o em todas as suas condições, seus habitos e sua indole.

Nalgumas regiões, as grandes cidades absorvem a riqueza e o lustre da nação, são ellas a morada da sociedade intelligente e elegante, e o campo é povoado pelos rudes camponios. $\mathrm{Na}$ Inglaterra, ao contrario, a metropole é mero ponto de reunião, ou de encontro geral das classes polidas, onde ellas consagram uma pequena porção do anno a um rapido tumulto de alegria e dissipação, e tendo-se permittido esta especie de carnaval, voltam logo aos habitos de vida componeza, mais conforme, segundo parece, ao seu genio. As mais diversas ordens da sociedade são, por isto, diffundidas sobre toda a superficie do reino, e as mais retiradas localidades fornecem specimens das differentes classes.

Os inglezes, com effeito, são em alto grau, dotados do sentimento rural. Possuem um vivo amor ás bellezas da 
natureza, uma inclinação accentuada para os prazeres $\mathrm{e}$ trabalhos do campo. Parece que essa paixão lhes é congenita. Mesmo os habitantes da cidade, nascidos e criados entre muros de tijolos e ruas barulhentas, entram com facilidade nos habitos ruraes, e manifestam tacto para as occupações rusticas. $\mathrm{O}$ negociante tem seu retiro abrigado na proximidade da metropole, onde mostra tanto zelo e orgulho na cultura de seu jardim de flores, e na maturação de seus fructos, quanto na direcção de seu negocio e na administração de sua empreza. Até os individuos menos aquinhoados da sorte, que são condemnados a passar a vida no meio do ruido e do trabalho, inventam alguma coisa que lhes lembrará o verde aspecto da natureza. Nos mais sombrios e negros bairros da cidade, a janella da sala da frente parece, não raro, um canteiro de flores; cada logar capaz de vegetação tem seu tapete de relva e seu canteiro de flores; e cada praça seu arremedo de parque; feito com um gosto pittoresco e brilhando com a vegetação fresca.

Os que unicamente vêem o inglez na cidade são levados a formar uma opinião pouco lisongeira de seu caracter social. Elle está não só absorvido pelos negocios, mas tambem distrahido pelos mil compromissos que lhe occupam 0 tempo, a attenção e os sentidos naquella vasta metropole. Elle tem, por este motivo um aspecto de pressa e de abstracção. Onde quer que esteja, acha-se na imminencia de ir para outra parte; no momento em que está falando de um assumpto, seu espirito já se acha occupado com um outro, e, quando paga uma visita de amizade, está a calcular como poderá economizar o tempo para outras marcadas para a mesma manhan. Uma immensa metropole, como éi Londres, é tida como tornando os homens egolstas e pouco interessantes. Em seus encontros casuaes e passageiros, elles não podem tractar sinão rapidamente de logares comuns. Não apresentam sinão a superficie fria de seu caracter, não tendo suas qualidades ricas e festivas tempo para se aquecer numa effusão. 
O gosto dos inglezes para a cultura da terra, e para a que se chama jardim de paisagem, é sem riva. Estudaram a natureza attentamente, e revelaram um sentimento exquisito de suas bellas fórmas e de suas harmoniosas combinações. Estes encantos que, noutros paizes, ella prodigaliza nas solidões agrestes, estão aqui reunidos, como por magia, em torno do retiro da vida domestica.

Nada pode ser mais imponente que a magnificiencia do scenario do parque inglez. Vastas planicies que se extendem como lençóes de um verde vivido, tendo aqui e alli grupos de arvores gigantescas, ostentando rica vestidura de folhagem, a pompa solemne de alamedas e clareiras nos bosques, com os veados nellas reunidos em bandos, a lebre saltando para o abrigo; ou o faisão tomando subitamente o vôo; o regato represado para se torcer em meandros naturaes, ou para formar uma bacia crystallina; - lago isolado reflectindo as arvores agitadas pelo vento, com a folha amarella dormindo em seu seio, e com a truta vagueando sem medo em suas aguas limpidas, emquanto algum templo rustico ou estatua silvestre tornada verde e humida pela edade, dá ao retiro um ar de santidade classica.

Estes não são mais que alguns aspectos do scenario do parque, o que porém particularmente me deleita é o talento inventivo com que o inglez orna as menos ostentosas habitações da vida média. A mais tosca morada, a menos promettedora e mesquinha porção de terra, nas mãos de um inglez de gosto, torna-se um pequeno paraiso. Com olhos bons julgadores, desde logo vê elle o que desta pode tirar, e pinta em séu espirito a futura paizagem. O pedaço de terra esteril ganha belleza sob suas mãos, e todavia as operações que produzem o effeito difficilmente são percebidas. $\mathrm{O}$ tractamento e direcção de algumas arvores, a poda cuidadosa de cutras; a feliz distribuição de flores de folhagem tenra e graciosa; a introducção de um verde declive de relva avelludada, a abertura parcial para um azul longinquo, ou para um brilho argentino de agua, tudo isto é aproveitado com um tacto delicado, com uma assiduidade ef- 
ficaz comquanto socegada, semelhante aos toques com que um pintor acaba sua obra favorita.

A residencia da gente de fortuna e de fino tracto no campo diffundiu um alto grau de gosto e elegancia na vida rural que desce até a mais baixa classe. O proprio lavrador, com sua cabana coberta de colmo, e sua estreita nesga de terra, procura o embellezamento de sua propriedade. A sebe bem tractada, o canteiro de relva diante da porta, os alegretes protegidos por uma guarnição occulta, a madresilva trepada pela parede e deixando pendentes suas flores ao lado da gelosia, o vaso de flores á janella, o azevinho, previdentemente plantado junto da casa, para illudir a tristeza do inverno, e dar uma apparencia de verde estio afim de trazer vida ao lar: tudo isto denuncia a influencia do gosto promanando de fontes elevadas, e chegando zo mais baixo nivel do espirito publico. Si o amor, como dizem os poetas em seus cantos, tem prazer em visitar uma casa de campo, deve ser a de um camponez da Inglaterra. A paixão pela vida rural entre as mais altas classes da Inglaterra teve um effeito grande e salutar sobre o caracter da nação .

Não conheço mais bella raça de homens que a dos fidalgos inglezes. Em vez da molleza e effeminação que caracterizam os homens de linhagem em muitos paizes, elles apresentam uma alliança de elegancia e de força, uma robustez de corpo e uma frescura de compleição, que eu julgo dever attribuir a viverem grande parte do tempo ao ar livre, e a usarem com tanto ardor dos recreios tonificadores do campo. Esses duros exercicios produzem tambem um tom saudavel de espirito e um caracter e uma virilidade e singeleza de maneiras que mesmo as loucuras e dissipações da cidade não podem perverter facilmente, nem jamais destruir. No campo, alem disso, as diversas classes sociaes parecem approximar-se mais livremente, e estar mais em condições de actuar uma sobre as outras. Não se mostram tão accentuadas as distincções entre ellas, e impossiveis de 


\section{-.. $251-$}

ser transpostas como nas cidades. O modo por que as terras foram distribuidas em granjas e pequenos casaes, estabeleceu uma gradação regular desde as classes de pessoas abastadas, ricos agricultores, pequenos proprietarios, até os camponezes lavradores; e, comquanto tenha, deste modo, ligado os extremos da sociedade, infundiu em cada grau intermedio um certo espirito de independencia. Isto, força me é confessar, não é tão geral hoje quanto outrora, por haverem os maiores proprietarios, nos ultimos annos de crise, absorvido os menores; e, nalgumas partes do campo, quasi anniquillado a forte raça dos pequenos proprietarios. Estes factos porém constituem, julgo eu, quebras casuaes no systema geral que eu expuz.

No serviço rural, nada ha que seja baixo ou desprezivel. Elle leva o homem ás scenas de grandeza natural e de belleza; entrega-o á acção de seu proprio espirito, influenciado pelos mais puros e elevados factores externos. Um tal homem pode ser simples e aspero, mas não pode ser vulgar.

Por este motivo, o homem do mais fino tracto nada acha de repulsivo nas relações com as mais baixas classes da vida rural, como succede quando tem elle de estar em contacto com as classes inferiores nas cidades. Põe de parte a distancia e reserva, e é feliz de banir distincções de classe, e entrar em gozo dos prazeres honestos e francos da vida em commum. De facto, os proprios divertimentos do campo, ligam continuamente os homens; e o latido dos cães e 0 toque da buzina de caça harmonizam todos os corações. Creio que é esta uma das razões por que, na Inglaterra, a nobreza e a aristocracia são mais populares nas classes inferiores do que em nenhum outro paiz; e porque as ultimas têm soffrido tão grandes pressões e vexames sem se queixar mais do que noutros paizes da desigual distribuição da fortuna e do privilegio.

A esta alliança da sociedade culta e da rustica pode attribuir-se o sentimento rural que se encontra na literatura 
ingleza; o frequente uso de illustrações da vida campezina; as incomparaveis descripções da natureza que abundam nos poetas da Inglaterra, que continuaram na mesma orientação desde "A Flor e a Folha" de Chaucer, e trouxeram para as nossas casas toda a frescura e fragrancia de uma orvalhada casa de campo. Os escriptores pastoris de outras terras parecem haver feito uma visita casual á natureza, e conhecer seus encantos geraes; mas os poetas inglezes com ella viveram e gozaram - cortejaram-na em seus mais secretos retiros - observaram-na em seus menores caprichos. Um galho não pode tremer sob a acção da brisa - uma folha fazer ruido no chão - uma gotta de diamante cahir na torrente - uma fragrancia exhalar-se da mais humilde violeta - nem uma margarida expor seu bello carmesim pela manhan, sem que seja isto mencionado por esses apaixonados e delicados observadores, e celebrado com alguma bella moralidade.

O effeito desta devoção dos espiritos de escol para com as occupações agrestes foi admiravel sobre a face do paiz. Uma grande parte da ilha é algum tanto plana, e seria monotona, si não fossem os encantos e palacios, e estar bordada com parques e jardins. Não tem abundancia de sublimes panoramas, mas, em geral, de pequenas scenas domesticas, de repouso agreste e de tranquillidade abrigada. Cada habitação rural, cada morada coberta de musgo é uma pintura; e como o caminho vae sempre variando e a vista é, a espaços, interrompida por bosquetes e sebes, os olhos são deliciados por uma continua successão de pequenas paizagens de uma belleza captivante.

O grande encanto, comtudo, do inglez é o sentimento moral que parece reinar nelle. E' associado no espirito com as ideas de ordem, de tranquillidade, de sobriedade, de principios bem estabelecidos, de uso encanecido e de costume respeitado. Tudo parece o producto do tempo, duma existencia regular e pacifica. A antiga igreja de architectura remota, com o seu portal baixo e massiço, sua torre gothica, suas janellas enriquecidas de ornato e de vidros pintados, 
escrupulosamente conservadas, seus soberbos monumentos de guerreiros e homens illustres do tempo antigo, antepassados dos senhores actuaes do solo; suas pedras tumulares recordando as successivas gerações dos camponezes varonis, cuja progenie ainda ara os mesmos campos, e ajoelhase em frente ao mesmo altar o presbyterio, um edificio original e irregular, em parte antiquado, mas reparado e alterado segundo o gosto das várias edades e dos diversos occupantes - a cancella e o atalho, dando sahida do cemiterio da igreja, atravez de campos deleitosos, e ladeado por sebes sombrias, segundo um direito immemorial de passagem - a aldeia da vizinhança, como suas casas de campo veneraveis, seu prado publico abrigado por arvores debaixo das quaes os antepassados da geração actual fizeram seus desportos - a mansão antiga da familia, estabelecida em separado, em algum pequeno dominio rural, mas olhando, com um ar protector, para a scena em derredor; todos esses aspectos communs á paizagens ingleza manifestam uma calma e tranquilla segurança, e a transmissão hereditaria de virtudes domesticas, e de ligações locaes, que falam profunda e commovedoramente em favor do caracter moral na nação.

E' quadro agradavel, quando na manhan de um domingo o sino atira sua soberba melodia atravez dos campos silenciosos, contemplar a companha dos lavradores em seus trajes domingueiros, com suas rudes faces e modesta alegria, enchendo socegadamente os verdes atalhos que levam á igreja; mas é ainda mais agradavel vel-os, á tarde, reunidos em torno das portas de suas casas rusticas, parecendo exultar nos confortos humildes e nos embellezamentos que suas proprias mãos espalharam em torno delles. E' o doce sentimento do lar, este calmo repouso da affeição na vida domestica, que, é, afinal, o gerador das mais firmes ou acrisoladas virtudes e dos mais puros prazeres.

\section{Traducção do Dr. Braz DE Sousa Arruda}

